\title{
ACUTE TRAUMATIC VENTRAL HERNIA
}

Dinesh H.N ${ }^{1}$, Anandaravi B.N², Raghavendra $\mathrm{M}^{3}$, Shreyas N4, Rambadri Narayan ${ }^{5}$

\section{HOW TO CITE THIS ARTICLE:}

Dinesh HN, Anandaravi BN, Raghavendra M, Shreyas N, Rambadri Narayan R. "Acute traumatic ventral hernia". Journal of Evolution of Medical and Dental Sciences 2013; Vol. 2, Issue 42, October 21; Page: 8038-8041.

ABSTRACT: A traumatic abdominal wall hernia is a rare type of hernia, which follows blunt trauma to the abdomen, where disruption of the musculature and fascia occurs, with the overlying skin remaining intact. Associated abdominal injuries are infrequent. An elderly male patient was seen in emergency within $6 \mathrm{hrs}$ of alleged history of bull gore injury, while working in the fields; he presented with complaints of pain abdomen and swelling in the right side of lower abdomen. On Examination, soft, tender swelling is noted in RIF with overlying contusion, which increased in size over the next two days, with expansile cough impulse. Swelling was completely reducible and visible peristalsis seen.USG Abdomen showed defect in right iliac fossa abdominal wall with bowel loops in subcutaneous plane. A local exploration was performed incorporating the site of injury. A defect in all layers of abdominal wall muscles in right iliac fossa with intact skin and subcutaneous tissue was found. Primary tension free repair of the defect in layers done with inlay placement of prolene mesh due to poor abdominal muscle tone. A high index of clinical suspicion is essential, as an accompanying hematoma often confounds the diagnosis. Mesh repair is desirable in the elderly with weak anterior abdominal wall so as to prevent the long-term complications of recurrences.

KEYWORDS: Abdominal wall, blunt trauma, hernia.

INTRODUCTION: Traumatic abdominal wall hernia (TAWH) are extremely uncommon type of abdominal hernia as far as the etiology is concerned. It is defined as a herniation through disrupted musculature and fascia, without skin penetration with no evidence of a prior hernia defect at the site of injury. Associated abdominal injuries are infrequent (1).TAWHs are seen following blunt trauma, for example, injury with handle bar or bull gore and road traffic accidents. In India bull gore injuries are frequently observed in villages. The pattern of injuries vary as described by various authors depending on the height of the victim, the height of the bull and relative position of the animal at the time of attack. The injuries are commonly seen in the abdomen and perineum (2). Although the surface area of abdomen is same as the chest, the abdomen suffers more injury than any other site. The reason appears to be lack of bony shield over the abdomen permitting the horn to engage and penetrate (2).TAWH as a rare entity has a confusing clinical picture and requires a high index of suspicion for prompt diagnosis and management. Such hernias, if missed, can result in high morbidity and if due attention is not given it may present with complications. TAWH are generally categorized into three major types - Type I, II and III depending upon the mechanism and size of injury. Here a 60yr old male who developed acute TAWH (Type I) following bull gore injury is reported.

CASE PRESENTATION: A $60 \mathrm{yr}$ old male patient presented to the emergency within 6 hrs of bull gore injury while working in fields, with complaints of pain and swelling in right lower abdomen. On primary survey he was hemodynamically stable and fully conscious; abdominal examination revealed a tender swelling $3 \times 4 \mathrm{~cm}$ with overlying contusion. It was thought to be haematoma and 
treated conservatively. Although the contusion improved over next 2-3 days, the swelling increased to $8 \times 10 \mathrm{~cm}$ with positive cough impulse and visible peristalsis. The swelling was completely reducible with a palpable defect in abdominal wall. Ultrasound abdomen revealed a $3 \times 4 \mathrm{~cm}$ defect in abdominal wall in right iliac fossa region, with a loop of bowel in subcutaneous plane with normal other visceral organs. A local exploration was done with a horizontal incision along langerhans' line over the swelling. Primary tension free repair of the defect in layers was done with prolene mesh placement in between external and internal oblique muscle layers. Excellent outcome was noted postoperatively and at 6 months follow up.

DISCUSSION: A traumatic abdominal wall hernia is defined as herniation of viscera through the muscles and fascia of the abdominal with the overlying skin remaining intact. First described by selby in 1906, it has a reported prevalence of approximately 1\% (3). They are produced by direct blunt trauma from an object that has insufficient force to penetrate the skin but sufficient tangential force to result in pressure induced disruption of the abdominal muscles and fascia(1). This is possible because the skin is more elastic than the rest of the layers (4). Damschen et al (5) reported that associated intra-abdominal injuries are infrequent. The apparent explanation for the infrequency of associated injury is the commonly observed resistance of hollow visceral to blunt injury is the fact that the trauma delivered in most cases is in areas away from parenchymal abdominal as reported by Yarbrough(9). TAWH associated with intra-abdominal injuries would necessitate exploratory laparotomy or extensive local incision.

Three types of hernia were reported by Wood et al. according to the size and mechanism of injury. Type I abdominal wall hernia involves a small defect caused by blunt trauma. Type II hernia is a larger defect which develops during high energy transfer events such as a motor vehicle crash or fall from a height. Type III hernias are those defects that involve the intra abdominal bowel herniation that has been described for deceleration injuries (1).

The diagnosis is usually made on the basis of history and examination. A tender subcutaneous swelling in abdominal wall with bruising of the overlying skin or swelling with a defect in the abdominal wall is the common clinical finding. Ultrasound and CT scan abdomen is helpful in diagnosis. In our case the patient was hemodynamically stable with clinically obvious herniation of bowel loops on $3^{\text {rd }}$ day of admission with no signs of intestinal obstruction. Ultrasound abdomen showed a defect in abdominal wall with normal other visceral organs, hence we proceeded with operative exploration. The type of repair to be performed must take into account the size of the defect, associated intra-abdominal injury and the tone of the abdominal muscles. The incision should be given directly over the swelling for proper enforcement of the herniated contents and defect (1). Prompt surgery is required to avoid complications such as incarceration or strangulation and subsequent morbidity.

CONCLUSION: TAWH should be suspected in a patient with tender, localised swellings of the abdominal wall following blunt trauma (1). A high index of clinical suspicion is essential, as an accompanying hematoma often confounds the diagnosis. Ultrasound and CT scan abdomen are helpful to arrive at a diagnosis. An approach of delayed repair has been reported to be more safe and feasible in low energy TAWH as hematoma and oedema resolution can be expected (3). In elderly 
male with a poor abdominal tone mesh repair after primary tension free closure of defect is the procedure of choice so as to prevent long term complications of recurrences $(1,3)$.

\section{REFERENCES:}

1. Rikki Singal, Usha Dalal, Ashwani Kumar Dalal etal. Traumatic anterior abdominal wall hernia: A report of three cases. J Emerg Trauma Shock. 2011; 4(1):142-145.

2. Meghraj Chawada, Utkarsh Ghavghave. Acute direct inguinal hernia resulting from penetrating abdominal trauma: case report. International journal of recent trends in science and technology. 2013; 5(3):130-131.

3. Navaratnam R. Abdominal wall hernia following blunt trauma: IJCRI. 2012; 3(9):26-28.

4. Ramesh B. Hatti, Suresh I. Basarkod, Vishwanath G, Vrushab Patil. Handlebar hernias: Case reports of rare traumatic abdominal wall hernias. Journal of Clinical and Diagnostic Research. 2011; 5(4):826-827.

5. Damschen DD, Landercasper J, Cogbill TH, Stolee RT. Acute traumatic abdominal hernia: case reports. J Trauma. 1994; 36:273-6.

6. Selby CD. Direct abdominal origin. JAMA 1906;47:1485. Hernia of traumatic origin. JAMA 1906;47:1485-6

7. Damschen DD, Landercasper J, Cogbill TH, Stolee RT. Acute traumatic abdominal hernia: Case reports. J Trauma 1994; 36:273-6.

8. Ganchi PA, Orgill DP. Auto penetrating hernia: A novel form of traumatic abdominal hernia: case report and review of the literature. J Trauma1996; 41:1064-6.

9. Yarbrough DR. Intra-abdominal injury with handlebar hernia: Case report and literature review. J Trauma 1996;40:116-8

10. Drago SP, Nuzzo M, Grassi GB. Traumatic ventral hernia: report of a case with special reference to surgical treatment. Surg Today 1999; 29:1111-4.

11. Tan EY, Kaushal S, Siow WY, Chia KH. Traumatic abdominal wall herniation. Singapore Med J. 2007; 48:270-71.

12. Rikki Singal, Raman Gupta, Amit Mittal et al. Delayed presentation of traumatic abdominal wall hernia; Dilemma in the management-Review of literature. Indian J Surg. 2012; 74(2):149-156.

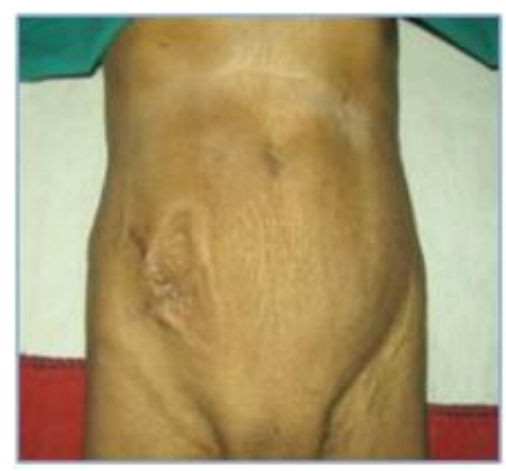

Fig. 1: Abdominal wall defect in right iliac fossa region with intact overlying skin and scar.

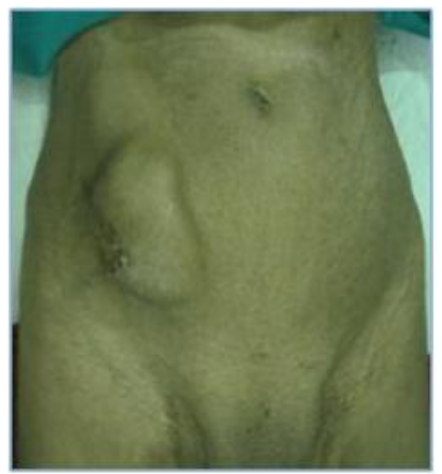

Fig. 2: Swelling in right iliac fossa region on coughing 


\section{CASE REPORT}

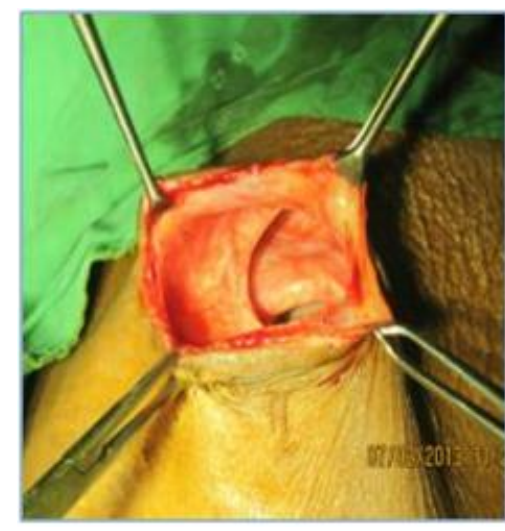

Fig. 3: Intraoperative finding of defect in all layers of abdominal wall musculature.

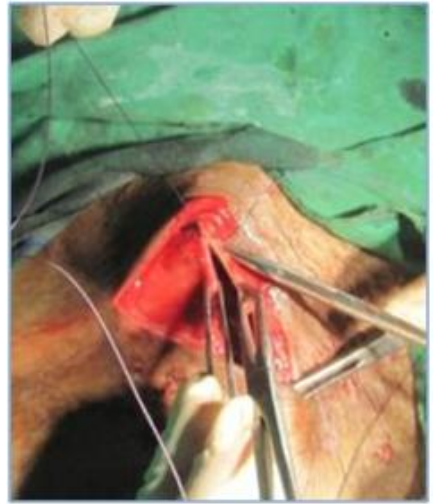

\section{AUTHORS:}

1. Dinesh H.N.

2. Anandaravi B.N

3. Raghavendra M.

4. Shreyas N.

5. Rambadri Narayan R.

\section{PARTICULARS OF CONTRIBUTORS:}

1. Associate Professor, Department of General Surgery, Mysore Medical College and Research Institute.

2. Assistant Professor, Department of General Surgery, Mysore Medical College and Research Institute.

3. Post Graduate Trainee, Department of General Surgery, Mysore Medical College and Research Institute.

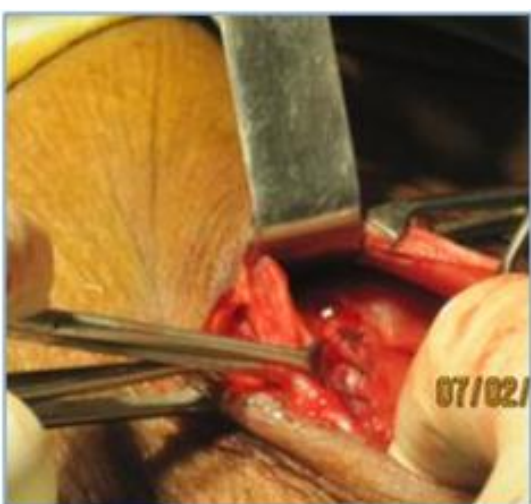

Fig. 4: Primary tension free closure of muscular defect.

Fig. 5: Repair of external oblique musculoaponeurotic layer defect.
4. Post Graduate Trainee, Department of General Surgery, Mysore Medical College and Research Institute.

5. Post Graduate Trainee, Department of General Surgery, Mysore Medical College and Research Institute.

\section{NAME ADDRESS EMAIL ID OF THE CORRESPONDING AUTHOR:}

Dr. Raghavendra M.

\# 216, PG Hostel for Men,

Behind Old Exhibition Building,

Irwin Road, Mysore - 570001.

Email - raghavendrahonna@gmail.com

Date of Submission: 03/10/2013.

Date of Peer Review: 04/10/2013.

Date of Acceptance: 10/10/2013.

Date of Publishing: 15/10/2013 